\title{
Entrevista: Prof. Dr. Miguel Nicolelis
}

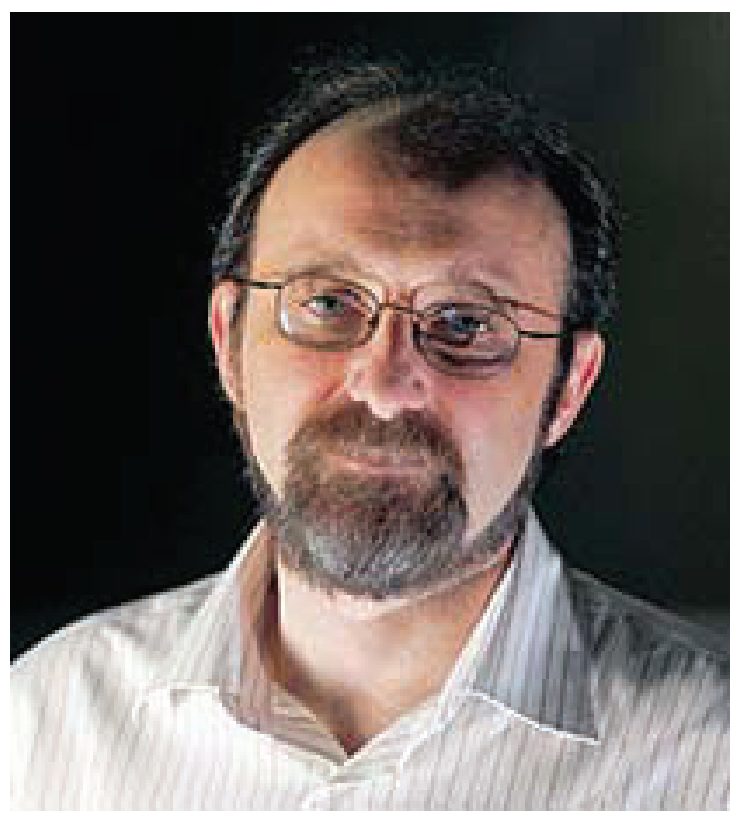

O expoente neurocientista Dr. Miguel Nicolelis, Professor Titular do Departamento de Neurobiologia da Universidade de Duke, formado pela 67ํㅡㄹ Turma da Faculdade de Medicina da USP, concedeu entevista à Revista de Medicina. Nela, fala sobre sua formação acadêmica e projetos de iniciação científica; o Ensino Médico, sua realidade e seus problemas; o Projeto Natal e como a ciência pode transformar a sociedade; os problemas da Ciência no Brasil; a interface Cérebro-Robô; o Prêmio Nobel e ainda dá recado aos estudantes brasileiros.

RM: Qual era a sua relação com a Faculdade de Medicina da USP na sua época de graduação? A que você dava mais importância e o que você mais gostava?

Prof. Dr. Miguel Nicolelis: Eu comecei na faculdade em 1979 e logo passei a fazer parte do CAOC (Centro Acadêmico Oswaldo Cruz). Aquela época era muito intensa, um período político muito importante na história do Brasil. Eu me envolvi rapidamente com o CAOC e com a Atlética (Associação Atlética Acadêmica Oswaldo Cruz), ao mesmo tempo. Fui diretor da Atlética primeiro - Diretor Geral de Esportes
- no terceiro ano e, no ano seguinte, eu participei da diretoria do $\mathrm{CAOC}$, o que era uma coisa rara naquela época (fazer parte de ambas as agremiações). Durante todo esse período eu participei muito das duas agremiações e comecei a fazer pesquisa no quarto ano, no Departamento de Patologia. Participei da criação da Disciplina de Informática Médica, que surgiu a partir do trabalho de pesquisa que eu iniciei na faculdade. A Disciplina foi criada junto com o Koichi Sameshima, que também era aluno da minha turma e que agora é professor da USP. Criamos isso como uso de computadores na Medicina e os alunos desse curso tinham aulas de Informática,

Entrevista realizada em 17 de feveireiro de 2008 por: Alan Saito Ramalho (Acadêmico do 3ำ ano do curso de Medicina da FMUSP) e Mateus Rozalem Aranha (Acadêmico do $2^{\circ}$ ano do curso de Medicina da FMUSP). 
aprendiam como mexer em microcomputadores. Isso foi primórdio do departamento que foi criado mais tarde, mas nessa época eu já tinha saído da faculdade. Quando me formei, imediatamente comecei a fazer Pós-Graduação e, por um ano e meio, fui professor da FMUSP. Então, eu fui de aluno a professor em sete anos, mais ou menos.

\section{R.M.: E você começou a fazer a pesquisa como aluno de iniciação científica?}

Prof. Dr. Miguel Nicolelis: Sim, eu fiz uma iniciação científica no quarto ano e, daí para frente, eu fiz uma carreira rápida na graduação, trabalhando em pesquisa básica. Consegui uma bolsa de iniciação científica da FAPESP (Fundação de Amparo à Pesquisa do Estado de São Paulo), depois uma de mestrado e uma de doutorado. E quando terminei meu doutorado, fui para os Estados Unidos.

\section{R.M.: Você acha que seu envolvimento com a pesquisa no quarto ano pode ter levado você a se dedicar integralmente à essa área?}

Prof. Dr. Miguel Nicolelis: Com certeza. Foi porque eu comecei a fazer pesquisa tão cedo que logo percebi que era isso o que eu queria fazer e foi essa iniciação que me deu certeza de que eu queria seguir isso como profissão. A maioria das idéias que eu levei para os Estados Unidos, para começar meu projeto de pós-doutorado, tive na graduação, na Faculdade de Medicina. Na época, eu trabalhava na parte de neurociência no laboratório do professor César Timolaria, um dos maiores neurofisiologistas que o Brasil já teve.

R.M.: Quais os principais problemas que você enfrentou na sua época de graduação? Você acha que esses problemas melhoraram nesses quase 30 anos?

Prof. Dr. Miguel Nicolelis: O problema, na época, era o fato de ser muito difícil trabalhar independentemente dos Professores Titulares. Inclusive, eu saí da FMUSP porque o Professor Titular do Departamento de Patologia simplesmente achou que eu não devia mais trabalhar lá, que eu não era persona grata no Departamento. A lei do momento era que ou se obedecia o Professor Titular ou se ele, por alguma razão, deixasse de gostar de você ou do que você fazia, você estava frito. Eu, na realidade, saí da USP por esse desentendimento com o Professor Titular da Patologia, que é um homem muito autoritário, um homem muito duro que, na minha opinião, foi muito maléfico para Faculdade de Medicina. Mas, por outro lado, foi muito bom para mim, porque eu tive de aprender a me virar. Percebi que ou eu seguia meu caminho e acreditava no que eu fazia ou não teria alternativa. Eu escolhi ir para frente.

R.M.: Você conhece o Ensino Médico em diversas partes do mundo. Você acha que o Ensino Médico brasileiro é um ensino de qualidade, se comparado com as escolas de medicina mundo afora?

Prof. Dr. Miguel Nicolelis: Eu acho que sim. Do ponto de vista prático, a nossa formação médica prática (eu não segui a carreira médica, mas minha formação médica me ajudou profundamente na minha pesquisa), de lidar com paciente, de fazer procedimentos, de estar envolvido com a dinâmica diária da Medicina, é muito melhor do que a graduação até mesmo nos Estados Unidos. Os alunos americanos, mais velhos, são melhores formados na parte básica, na parte científica. O foco teórico dado a eles é muito mais profundo no sentido de examinar mais detalhadamente as bases fisiopatológicas das doenças. Mas a parte prática deles é muito fraca. Um médico americano, quando chega à residência, não sabe muito da vida diária da Medicina, a residência é um momento crucial para eles e é um esforço ainda maior que o nosso como residente no Brasil. Temos também de entender que o aluno americano, que chega à universidade com 22 anos, depois de passar pelo college para Medicina, é um aluno mais sério, dedicado e focado. O custo é muito alto para se estudar Medicina lá, o pessoal leva mais à sério. $O$ desempenho nos exames, no final das contas, analisando a performance teórica dos alunos americanos, é melhor; porém, na performance prática, do dia-a-dia da Medicina, os médicos brasileiros jovens, no geral, são mais voltados ao paciente, porque eles têm uma formação humanística e técnica de lidar com o paciente melhor. O americano é muito mais versado em tecnologia, ele tem muito mais apego à parte numérica, à parte tecnológica, ao diagnóstico laboratorial, mas tem muito menos facilidade em interagir com o paciente e no exame propedêutico, o que no Brasil é muito forte. Eu acho, entretanto, que o curso médico em todo lugar do mundo está sofrendo uma mudança muito grande. A Medicina está mudando muito e esse movimento também tem que ser incorporado no Brasil, porque, se não, nós vamos ficar para trás.

R.M.: Qual é exatamente essa mudança que a medicina vem sofrendo?

Prof. Dr. Miguel Nicolelis: Hoje em dia, vocês, que estão no curso médico, sabem que a informação médica aumentou muito, é muito difícil dominar e 
transmitir um conhecimento mínimo - você tem que imaginar que o curso médico nos EUA é de quatro anos, e não de seis, como é aqui no Brasil. E na Duke (Universidade de Duke), por exemplo, os alunos tiram um ano pra fazer pesquisa. Então, na realidade, o curso médico deles tem três anos. Eles trabalham em nossos laboratórios e desenvolvem pesquisa por um ano. Mas, o que está acontecendo é a dificuldade de equilibrar a explosão do conhecimento, a explosão de novas técnicas e a questão de lidar com a parte humana do paciente, que nos Estados Unidos está meio abandonada, cada vez pior, eu diria. Eu, por exemplo, se tiver de me tratar ou tratar minha família, o tratamento é pegar o avião na Carolina do Norte e vir para o Brasil, vir para São Paulo, num dos melhores hospitais do Brasil. Porque eu me sinto melhor tratado, melhor visto como ser humano, do que lá na Duke, que tem o quarto maior hospital dos Estados Unidos. A dificuldade encontrada hoje, na minha opinião, é de como transmitir o essencial e como ensinar o aluno de medicina a aprender por si mesmo e não transmitir a ele tudo o que existe de informação. Como ensinar um algoritmo de aprendizado eficiente que permita que esse aluno de Medicina vasculhe por si mesmo o conhecimento e carregue, para o resto da sua carreira, um método de aprendizado eficiente para si mesmo. A questão é como otimizar o aprendizado pra cada indivíduo. Esse é o grande desafio do ensino médico, na minha opinião, hoje em dia.

\section{R.M.: O que o levou a imaginar um instituto referencial de neurociência em Macaíba, uma cidade com baixíssimo IDH e o que o encorajou a lutar pela concretização do projeto?}

Prof. Dr. Miguel Nicolelis: Eu, basicamente, depois de vinte anos fora do Brasil, achei importante trazer para o Brasil algo que eu tivesse aprendido fora daqui e que contribuísse, de alguma maneira, para esse momento do país, que eu vejo como um momento histórico, de construção da sociedade brasileira e do país que queremos ter. Eu acredito, há muito tempo, antes mesmo de começar o projeto, que a ciência pode ser um agente fundamental na construção de uma sociedade mais justa, mais igualitária e mais dinâmica, algo que o Brasil precisa urgentemente. E foi aí que nós idealizamos a proposta de utilizar a ciência como agente de transformação social e criamos um projeto piloto, o projeto de Natal, para demonstrar que, se criássemos um centro de excelência científica, mesmo num lugar tão pobre e com sérios problemas, como Macaíba, seríamos capazes não só de desenhar um projeto de transformação social da comunidade, mas também de atrair, usando a ciência, investimentos que pudessem ampliar e diversificar a economia da região e com isso, também, contribuir para a melhoria do grau de educação, de atendimento médico e de desenvolvimento humano. E o que está acontecendo? Está se formando uma grande bola de neve. Hoje nós temos, dentro do Campus do Cérebro, que está distribuído entre Macaíba e a periferia de Natal, mil crianças participando de um curso de educação cientifica infanto-juvenil, que vai se transformar, daqui a um ano e meio, numa escola regular, de capacidade para 5.000 crianças em tempo integral, pública, de acesso a todas as crianças da região. A criança começará seu processo educacional logo depois de nascer, porque as mães vão ter acesso a essa escola durante o período de gravidez. E para isso, nós já construímos e inauguramos uma clínica da mulher ao lado da escola, onde vamos atender 20 mil consultas por ano de mulheres jovens, pré-natal de alto risco e também fazer prevenção de câncer da mulher, numa forma de tentar, basicamente, melhorar as condições de saúde pública da mulher e da criança. Portanto, a criação desse instituto de ponta de neurociência alavancou um projeto educacional e um projeto de atendimento médico primário que vai permitir que tudo o que a gente aprenda sobre o cérebro

possa ser aplicado na melhoria, na otimização, tanto da educação dessas crianças e das mães, quanto na melhoria da qualidade de saúde pública da região. E o último passo é construir em volta do Campus do Cérebro um parque tecnológico de pesquisa industrial que nos permita ter, no Brasil, o primeiro parque de Neurotecnologia do mundo. O curioso é que muita gente achava que isso era uma coisa louca, um sonho doido, e, de repente, nós estamos sendo procurados pelas maiores empresas do mundo, que ouviram falar do projeto (saiu um artigo nesse mês, na Scientific American, mostrando como esse projeto pode ser clonado para outros países). Nós estamos começando a regimentar apoio da iniciativa privada que trabalha nessa indústria (que eu gosto de chamar de indústria do cérebro), que vê o Projeto de Natal como um novo paradigma no desenvolvimento de novas tecnologias para o tratamento de doenças 
neurológicas. Além disso, a idéia é que esse projeto seja auto-sustentável e que possa, no futuro, ser clonado para outras regiões do Brasil e do mundo.

\section{R.M.: E quais foram os principais obstáculos que você e sua equipe enfrentaram para realizar esse Projeto?}

Prof. Dr. Miguel Nicolelis: Acho que o maior obstáculo foi a descrença. O fato de, no Brasil, as pessoas terem perdido um pouco a ousadia. Eu acho que o nosso grande drama enquanto país, depois do Golpe Militar de 1964 e depois da redemocratização do país, foi a perda da ousadia, a perda da crença de que é possível sonhar grande e realizar, no Brasil, grandes projetos, que vão muito além da média do que se faz no país. Temos muito medo de ousar no Brasil, porque temos muito receio de falhar, e esse receio de falhar inibe as pessoas de fazerem coisas que tenham peso, que tenham repercussão e que sejam meritórias. Se você não ousa, você nunca vai realizar nada diferente. A primeira resistência foi da própria classe científica brasileira, que achou uma loucura vir para o Nordeste/Natal e ficou preocupada com o fato de perder possíveis recursos para suas pesquisas, achando que nós iríamos drenar esses recursos, o que é curioso, porque, se era um projeto que não tinha nenhum mérito, ninguém teria de ter medo, pois não iria conseguir competir com ninguém. E o que, basicamente, nós mostramos é que estamos construindo isso sem ter que usar recursos que normalmente estão disponíveis, no Brasil, para os cientistas. Nós estamos trazendo para o país novos recursos, privados, e estamos incentivando, com o nosso projeto, o governo federal a perceber que ciência faz bem para o país, que é preciso pôr mais recurso (na ciência). A descrença original foi rebatida com a ação, e hoje é o projeto científico brasileiro de mais renome fora do Brasil. É um projeto que está começando, engatinhando e mesmo assim já tem o reconhecimento que nenhum outro projeto cientifico, que eu conheço no país, tem. Então, se a ousadia é bem conduzida, ela paga o seu preço.

R.M.: O uso da ciência como ferramenta de desenvolvimento social é uma constante nas suas entrevistas e nos artigos que você escreve. Numa entrevista para a Carta Capital, você afirmou, sobre o Projeto de Natal, que "o princípio era usar a ciência para transformar a realidade de uma comunidade, de tal sorte a criar um núcleo de auto-sustentabilidade". O que seria, exatamente, um núcleo de auto-sustentabilidade e de que forma

\section{o uso da ciência pode criá-lo?}

Prof. Dr. Miguel Nicolelis: Uma vez que você faz ciência de alto nível (ciência básica ou aplicada de alto nível), você vai descobrir novas coisas, novas tecnologias, novas terapias. Vai descobrir novos conhecimentos que precisam ser disseminados. Tudo isso tem um valor agregado. Se você conseguir usar o valor agregado desses produtos, que são produtos tecnológicos, de conhecimento, para gerar riqueza, receita e aplicar essa receita em projetos educacionais, projetos de atendimento de saúde e mais pesquisa, você está pagando seus custos (que são educação, saúde e pesquisa) com a receita que você produziu com a inovação que você mesmo gerou. Dessa forma, a receita que entra como fruto de suas idéias paga as suas ações sociais e alimenta as suas novas ações de inovação, que têm que ser constantes, evidentemente. Isso que é um modelo auto-sustentável: um modelo que precisa de um capital inicial para sair do papel, mas quando começa a gerar produtos de alto valor agregado (conhecimento e tecnologia), podem gerar receita pra sustentar a sua ação social, educacional, médica. Assim, você cria uma coletividade, uma comunidade auto-sustentável, que é exatamente a nossa proposta. A longo prazo, o que queremos aqui é criar uma cidade da ciência, uma cidade do cérebro. As pessoas que morarem na periferia de Natal estarão engajadas nos diferentes níveis de produção da indústria do conhecimento, gerando receita para que a gente possa ter as melhores escolas do Brasil, as melhores universidades do Brasil, as melhores empresas do Brasil. Aliás, eu recebi uma consulta da própria (Universidade de) Duke, que está interessada em discutir a possibilidade de abrir um Campus dela aqui em Natal, o que seria algo inédito. Uma universidade americana abrir uma faculdade de medicina, de engenharia, de negócios (eu não sei exatamente no que ela está interessada). É uma das melhores universidades do mundo que abriria um campus e atrairia estudantes brasileiros que, para ter um currículo de altíssimo nível, iriam pra Natal. É possível que muitos de nós, que vivemos em São Paulo, deixemos de fazer o vestibular da USP para fazer o vestibular da Duke. Cito a (Universidade de) Duke porque ela me conhece, mas há várias universidades americanas falando em abrir campi delas em Natal. Com isso, muda-se completamente o perfil da região. Você traz o talento nacional para estudar numa universidade americana em território nacional. Seria uma revolução tremenda. 
R.M.: Isso revolucionaria todo o ensino superior no Brasil...

Prof. Dr. Miguel Nicolelis: Geraria competitividade. Nós, que vivemos ou crescemos em São Paulo, temos uma ou duas opções, quando chegamos aos 17,18 anos e prestamos vestibular. "Ou eu vou para USP ou eu vou para Unicamp... ou para Paulista (EPM/Unifesp)". As opções que nós temos são muito restritas. Nós nos formamos e ficamos em São Paulo, porque a família está aí, tudo está aí, a inércia nos mantém aí. Agora, se você tem oportunidades ainda melhores que a USP, para estudar em outras regiões do Brasil, o talento nacional começa a se deslocar para todo o território nacional.

R.M.: A região em que está o campus do cérebro é uma região que abriga uma fauna e uma flora muito características do Brasil, que é a caatinga. Além de estar próximo à Floresta Amazônica e ao cerrado. Uma vez que desenvolvimento sócioeconômico-cultural implica, de certa forma, em degradação ambiental, você acha que existe um risco de isso acontecer? Há algum esforço para evitar que tal degradação ambiental aconteça?

Prof. Dr. Miguel Nicolelis: Primeiro, Macaíba está na zona do agreste, ou seja, não está na caatinga. Está a mais ou menos $50 \mathrm{~km}$ do começo da caatinga. É preciso viajar mais ou menos uma hora para começar o sertão que, na realidade, até hoje está abandonado do ponto de vista econômico. A Floresta Amazônica, evidentemente, está a mais de 4 mil quilômetros, o que não é nenhum motivo de preocupação imediata. Não há nenhum perigo imediato de um projeto no Nordeste afetar, a não ser indiretamente, a Amazônia. Mas em termos genéricos, se você fizer um projeto ou tiver uma visão estratégica que não leva em conta a preservação ambiental, ele vai, fatalmente, degradar o ambiente natural da região. Porém, hoje em dia, você pode fazer um projeto estratégico de desenvolvimento econômico de país, mesmo da caatinga e da Floresta Amazônica, sem incorrer em nenhum tipo de devastação. O que você precisa, todavia, é fazer com que o valor do ambiente intocado, do ambiente como ele está, seja maior, do ponto de vista econômico, do que o ambiente destruído. Porque você não vai conseguir impedir as pessoas de tentarem sobreviver, deixar os filhos passarem fome porque não se pode derrubar uma floresta para plantar mandioca. Temos de criar uma forma de as pessoas conseguirem alimentar e criar seus filhos sem precisar degradar o ambiente. É por isso que temos de investir em educação. A educação ambiental é parte disso (os nossos meninos em Natal vão começar a ter um curso específico de educação ambiental dentro do currículo de ciência deles). Temos, também, de mostrar que existem formas de manejo do ambiente em que você consegue fazer o desenvolvimento sem destruir o habitat natural ao seu redor, mesmo na Floresta Amazônica, por exemplo. O que não faz sentido é a Floresta Amazônica ser derrubada pra você plantar soja ou fazer pastagem. Isso é um absurdo. Mas isso ocorre porque as pressões econômicas indiretas fazem com que a fronteira agrícola e a fronteira agropecuária do Brasil invadam a periferia da Amazônia. Nós estamos escrevendo um documento para o Presidente da República com uma sugestão da comunidade internacional de aferir um valor ecológico à Floresta Amazônica, que seria pago pela comunidade internacional em prol da preservação da Amazônia, com a redução dos subsídios agrícolas que os Estados Unidos e a Europa têm com relação aos produtos agropecuários. Pois são esses subsídios agrícolas, entre outras coisas, que forçam a invasão da Amazônia para reduzir o custo da produção brasileira para esta poder pagar a tarifa que a comunidade européia e os Estados Unidos têm. A nossa proposta é que, como a Floresta Amazônica é um dos maiores seqüestradores de carbono do mundo, o mundo tem de ter responsabilidade em fazer com que o preço de uma árvore em pé seja maior do que o preço de uma árvore derrubada. A forma de fazer isso é o mundo pagar pelo benefício que a Floresta Amazônica traz para ele. A ciência permite que você faça esse tipo de elaboração.

R.M.: Você deixou o Brasil em 1988, quando o país acabara de emergir de duas décadas de Ditadura Militar, um período em que a produção científica foi mínima...

Prof. Dr. Miguel Nicolelis: Sem dúvida, foi uma devastação muito grande.

R.M.: Hoje, 20 anos mais tarde, quais são, na sua opinião, as perspectivas para a ciência brasileira?

Prof. Dr. Miguel Nicolelis: As perspectivas são excelentes, ótimas. O Brasil aumentou muito sua produtividade e investiu. Mas, o Brasil precisa investir em ciência grande. É preciso investir em idéias grandes. Não pode só ficar limitado a publicar papers e aumentar seu número de publicações, pois, se esses papers não tiverem nenhum impacto no conhecimento mundial, isto é, nenhum impacto na ciência mundial e não criarem nenhuma inovação 
do conhecimento, não adianta nada. O número total de papers é um indicador muito interessante. Mas ele é somente o primeiro indicador de impacto científico. Se você só dizer que o Brasil passou a Suíça em número de papers publicados, sendo hoje o $15^{\circ}$ do mundo em produção, não quer dizer muita coisa, porque a Suíça tem 5 milhões de habitantes. Se não for dividido per capita e não se medir qual o impacto dos trabalhos que o Brasil produz, a quantidade de papers não representa muita coisa. Eu posso citar outros indicadores como o fato de a Suíça ter 25 prêmios Nobeis. Então, existe um avanço, sim, mas existem amarras muito grandes que seguram o desenvolvimento da pesquisa brasileira. A pesquisa tem de ser encarada como um investimento estratégico do país. Esse investimento tem de ser feito com cuidado, mas com ousadia. E há de ser investido em gente, que tem de ser preservada, a quem tem de ser dada liberdade de poder trabalhar sem as dificuldades que, por exemplo, existiam quando eu fui embora do Brasil, quando, se você tivesse uma idéia ou quisesse trabalhar e o professor titular não concordasse com você, adeus. Era preciso arrumar a mala e ir embora porque lá você não teria condições de ficar de jeito algum. Eu saí da Faculdade discordando da postura e da atitude do professor titular, e aos poucos meu laboratório foi perdendo telefone e todo tipo de infra-estrutura por causa da minha discordância em relação ao chefe do departamento. $\mathrm{E}$ isso não pode acontecer. Mas acontecia. Havia duas opções: desistia ou ia embora para outro lugar. Essa visão foi mudando, mas ela ainda não acabou. Ainda existe essa visão dos feudos no Brasil. É preciso que se invista nas pessoas de talento, que se repatrie jovens talentos que não tinham oportunidade para ficar no Brasil e é preciso que se invista em qualidade, em gente competente e criativa, pois esse é o único jeito de se fazer pesquisa de alto nível.

\section{R.M.: Hoje existe um mercado mundial de conhecimento, em que o conhecimento é muito valioso...}

Prof. Dr. Miguel Nicolelis: É verdade que o conhecimento hoje, apesar de não ser uma commodity, é um produto altamente agregado, que tem um valor muito importante no desenvolvimento das nações e no comércio das nações.

R.M.: Você acha que o Brasil e a ciência brasileira estão preparados para essa realidade da ciência mundial, com esse mercado do conhecimento?
Prof. Dr. Miguel Nicolelis: O Brasil ainda não está bem preparado, porque ainda tem dificuldade de competir num sistema meritocrático. O Brasil e a comunidade científica brasileira ainda têm dificuldades em sair das querelas provincianas e se encaixar num mercado global de ciência, não só por culpa das pessoas, mas por uma série de coisas. É culpa também da legislação nacional, da dificuldade de importar e trazer novos equipamentos e materiais de consumo. É inacreditável a dificuldade de importar materiais para rotina da pesquisa para o Brasil. A legislação brasileira ainda não está adequada a um modelo global de execução científica. Se eu fosse contar as dificuldades para trazer, importar equipamentos para Natal... é uma loucura. E toda dinâmica tributária, trabalhista não são voltadas para uma atividade científica produtiva. Por exemplo, no Brasil não há incentivo algum para uma pessoa fazer uma doação para um projeto científico. Nos Estados Unidos, doa-se 20 milhões de dólares para a Universidade ou para um Laboratório e tem-se uma vantagem fiscal fenomenal. Isso ajuda o governo a arrecadar recursos privados para investir em áreas estratégicas e em ciência. Como nós não temos uma visão estratégica de país, não temos uma visão estratégica de ciência para o país. E esse é o drama. Nossa visão é tão míope que ela se limita a "qual é o próximo escândalo que vai sair na capa da Folha". Isso são as notícias do Brasil. Não temos uma cultura de pensar, estrategicamente, o que tem de mudar. Temos exemplos de quem mudou e se deu muito bem: a Vale (do Rio Doce), a Petrobrás, a Embraer. São exemplos clássicos de empresas que apostaram numa visão estratégica e global. Hoje são empresas conhecidas no mundo inteiro. Do ponto de vista científico, o Brasil precisa de uma visão estratégica. Repito que é necessário ter uma visão estratégica de ciência, e nós não temos ainda.

R.M.: Sobre a sua pesquisa, a interface cérebrorobô, quais seriam as principais aplicações dessa tecnologia, além da movimentação de próteses?

Prof. Dr. Miguel Nicolelis: A primeira delas, sem dúvida nenhuma, é a reabilitação. Essa, no momento, é a grande esperança da nossa equipe. Nós estamos avançando rapidamente. Em relação ao último trabalho que estamos desenvolvendo (as próteses para membros inferiores), houve um avanço muito rápido nos últimos dois anos. Teremos esse ano alguns experimentos a serem feitos, que já estão planejados, e que vão dar um passo decisivo para que possamos pensar no ano que vem, provavelmente, 
em já ter uma transformação desses resultados em algo com uma transformação clínica mais imediata. No entanto, há várias possibilidades futuras que dependem da invenção, ou melhor, da descoberta de métodos não invasivos para se registrar a atividade elétrica do cérebro. Hoje, nós temos de fazer isso através de implantes corticais, que num paciente com uma seqüela neurológica severa justifica-se devido ao grande custo-benefício. Mas, para o ser humano, sem nenhum problema médico, existe um problema ético. Um problema grave em querer-se fazer um implante cortical para melhorar a performance desse indivíduo. Porém, eu, supreendentemente, descobri, nos últimos meses, que a Microsoft criou uma divisão de interface cérebro-computador. Eles estão tentando descobrir meios de, com métodos não-invasivos, usar a atividade elétrica do cérebro para controlar componentes de um laptop ou um desktop normal. O que nossa pesquisa descobriu é que à medida que se interage diretamente com robôs e artefatos computacionais, o cérebro assimila essa ferramenta como sendo parte do próprio corpo do paciente. Isso, evidentemente, mudaria por completo a forma de interagirmos com o computador. Essa é uma direção que vai avançar rapidamente, porque as grandes empresas de computação estão se interessando pelo assunto. Essa área está crescendo numa velocidade muito grande. Eu vejo a possibilidade de, nas próximas décadas, ter-se aplicações que não sejam só para pacientes com lesão neurológica.

\section{R.M.: Você acha que essa tecnologia poderia ser usada para o desenvolvimento de tecnologia bélica, como novas armas.}

Prof. Dr. Miguel Nicolelis: Tem muita gente que gostaria que isso fosse feito. Eu, particularmente, nunca participei de nada nesse sentido e não acredito que, nesse instante, haja qualquer chance de uma coisa dessa ser produzida. Eu acredito que a sociedade como um todo não vai permitir que uma tecnologia que possa ter um impacto tão benéfico para a humanidade possa ser usada para essa finalidade. E, do ponto de vista científico, não existe nada que possa ser benéfico para aplicações bélicas, isto é, não existe nenhum resultado e nenhuma perspectiva em usar isso em qualquer tipo de arma. Claro que deve ter gente pensando nisso, mas eu, particularmente, que participo de reuniões continuamente, nunca ouvi ninguém falar nada, nem ouvi nenhuma idéia que tivesse qualquer tipo de mérito científico nesse sentido. Mesmo porque todo desenvolvimento atual é feito com técnicas invasivas e nem os americanos seriam capazes de imaginar a realização de implantes em soldados para poder usar algum tipo de arma.

R.M.: O senhor é visto, no Brasil, como o futuro primeiro brasileiro a receber o prêmio Nobel. Você foi o primeiro brasileiro a inscrever uma pesquisa no Salão do Nobel e existe a expectativa de que você seja premiado. Como o senhor lida com essa expectativa.

Prof. Dr. Miguel Nicolelis: Eu tento não discutir muito isso, porque eu fico lisonjeado que as pessoas pensem isso. Mas eu não me motivo, não trabalho e não faço o que eu faço em função de uma expectativa de qualquer tipo de premiação. Eu aprendi, ao longo desses 20 anos, que qualquer prêmio, não precisa ser o Nobel, é um prêmio subjetivo, definido por um grupo específico de pessoas, que tem critérios muito pessoais. E no caso de um prêmio com o prestígio do prêmio Nobel, é algo que envolve um grau de complicação política bem elaborada. Somente visitando, como eu visitei, o Instituto Nobel para se perceber a dimensão que é o processo decisório. Portanto, é muito difícil (que minha pesquisa seja premiada), porque a Medicina e a Fisiologia, atualmente, transformaramse em ciências muito reducionistas. A maioria dos pesquisadores trabalha em um gene ou uma proteína ou um receptor específico. Como o Comitê Nobel é formado de médicos suecos que trabalham nessa área, eles, na realidade, trabalham nesse nível de análise: um nível molecular, nível genético, etc... Então, é muito raro uma premiação recompensar a biologia dos sistemas, que é a área em que eu me insiro. Porém, eu fiquei muito feliz pelo convite de dar a Aula Nobel em Novembro, que foi muito emocionante para mim. Representar o Brasil foi o ponto alto da minha carreira. Lembrar de tudo que aconteceu para aquele dia poder acontecer, assinar o livro oficial (que é um livro que registra todas as aulas do Instituto Nobel, desde o começo do século passado) e ser o primeiro brasileiro a assiná-lo, para mim, já foi o prêmio. Não preciso de muita coisa mais. Porque isso já foi uma recompensa para mim. $\mathrm{Na}$ 
vida profissional, acredito, temos de ter recompensas pequenas, que, no cumulativo, fazem-nos sentir que valeu a pena todo esforço e sacrifício. Eu entendo a expectativa do Brasil, da sociedade e da comunidade científica brasileira e espero que um brasileiro ganhe o prêmio, para que as pessoas possam acreditar, como eu já acredito, que o Brasil têm cientistas fenomenais, atunado tanto no Brasil quanto fora do Brasil. Pessoas de competência excepcional. Aliás, é muito estranho que o Brasil não tenha ganho (o Prêmio Nobel) até hoje. Muitas pessoas mereciam ter ganho, em várias categorias, inclusive Medicina. Eu espero e torço para que alguém ganhe-o, para que esse complexo de inferioridade seja eliminado. Não devemos ter nenhum tipo de complexo em relação a quaisquer outros pesquisadores. É só que a tradição de países como Estados Unidos e os europeus permitiu que eles tivessem um investimento muito maior, além de uma cultura mais voltada à ciência. O Brasil vai ganhar seu prêmio Nobel e isso vai acontecer logo.

\section{R.M.: Qual o recado que você daria aos estudantes brasileiros que sonham em ser grandes cientistas ou grandes médicos, enfim, que sonham em ousar como você ousou?}

Prof. Dr. Miguel Nicolelis: $O$ meu recado é muito simples: as pessoas têm de acreditar nas suas paixões e nunca desanimar quando alguém mais velho ou mais poderoso disser que essas ambições e esses sonhos não são para nós. Eu ouvi isso demais quando estava na Faculdade. Mas, ao mesmo tempo, encontrei algumas pessoas como o Dr. César Timo-laria que disseram que esses sonhos que eu tinha, essas ambições, eram possíveis e eu tinha de persegui-las com a maior energia possível. Então minha mensagem é essa: que os meninos e meninas da Faculdade acreditem em si mesmo, acreditem nos seus sonhos e não aceitem ser claudicados ou diminuídos pela autoridade vigente do momento. A autoridade existe para ser desafiada e para ser combatida, do ponto de vista intelectual, evidentemente. A maior lição que eu aprendi nos Estados Unidos foi ver um aluno do colegial desafiar um professor titular, e o professor aceitar o desafio e responder, sem irritar ou achar que a pessoa era deselegante ou mal-educada. Ele aceitou o desafio porque lá, pelo menos até pouco tempo atrás, o desafio à autoridade era norma, era aceito. Temos todo o direito, não importa quem seja, de, do ponto de vista lógico, intelectual, não acreditar em uma afirmação que não seja baseada em fatos ou em dados. À cada aluno da Faculdade minha recomendação é: perseguir seu sonho com a maior dedicação, a maior paixão e acreditar em si mesmo. Acreditar, acima de tudo, no seu próprio taco. Isso porque, quando eu saí da FMUSP, há vinte e um anos atrás, muita gente falou para mim que minha carreira tinha acabado. Eu, no entanto, usei isso como motivação para construir uma careira longe do Brasil para poder um dia voltar. Eu sempre tive em mente que queria voltar (à FMUSP). Mas eu queria voltar pela porta da frente da Faculdade, apesar de eu ter saído pela porta de trás. Eu quero voltar pela porta da frente e provar para as pessoas, que ainda estão aí, que me fizeram ir embora que elas tinham cometido um erro. Eu nem preciso falar quem eles são, nem preciso tripudiá-los, porque eles sabem que cometeram um erro. $\mathrm{O}$ que os meninos aí tem de pensar é que o futuro pertence a cada um de vocês e são vocês mesmos que vão fazer o seu próprio futuro. Ninguém vai poder impedir que vocês realizem o que vocês querem realizar, porém, tudo tem um preço. E o preço é alto. É um preço que requer dedicação, empenho e uma crença muito grande. Mas eu acredito piamente que cada um de vocês aí da Faculdade tem tudo para poder realizar o que quer que seja que cada um de vocês queiram da vida.

R.M.: A sua palestra no XXVI COMU gerou uma repercussão enorme na FMUSP. Até hoje vemos alunos comentando nos corredores. Os alunos comentam conosco, no Departamento Científico, sobre o senhor. Todos te tomam como uma referência. Nós gostaríamos, portanto, que você fizesse a abertura do Congresso Médico Universitário desse ano (XXVII COMU), no dia 13 de Outubro de 2008. Fica desde já o convite. Muito obrigado pela entevista. Agradecemos em nome de todo o Departamento Científico da FMUSP. 